\title{
A EDUCAÇÃO AMBIENTAL NA FLORESTA DE CAXIUANÃ: RECONSTITUINDO SIGNIFICADOS
}

\author{
Marilena Loureiro da SILVA ${ }^{1}$ \\ Universidade Federal do Pará \\ marilenals@ufpa.br
}

Resumo: O presente artigo discute a necessidade de aproximação entre as práticas culturais e educativas realizadas no interior de florestas, com toda a sua diversidade e complexidades, e aquelas práticas culturais e educativas realizadas nas cidades. Tenta-se formular discussões teóricas em torno da importância da educação ambiental para a superação da separação entre sujeitos humanos e natureza, relacionado a necessidade de instalar novas formas para esta relação baseadas na busca de compreensão da complexidade ambiental. Para tanto, apresenta-se uma revisão de literatura acerca da situação dos recursos florestais no estado do Pará, bem como a análise de como esses recursos são percebidos como separados da dinâmica da vida da cidade. São discutidos ainda os resultados da pesquisa realizada na Floresta de Caxiuanã, no Pará, relacionado à análise das práticas de educação ambiental fundamentadas na aproximação com a natureza e seus recursos.

Palavras-chaves: Recursos Florestais. Cultura. Prática educativa.

Abstract: This article discusses the approach necessity between the cultural and educational activities made in the forests, with all its diversity and complexity to those practices activities in these cities. it is tried to formulate theoretical discussions about the importance of environmental education in overcoming the separation between nature and human subjects, related to the need of install new forms for this relationship based on the search for understanding environmental complexity. To this end, we present a literature review about the forest resources in the state of Para, as well as analysis of how these features are perceived and separate from the dynamics of city life. It's also discuss the results of research conducted at the Forest of Caxiuanã, in Pará, related to pratical analyse in environmental education based on the approach to nature and its resources.

Keywords: Forest Resources. Culture. Educational Practice.

\footnotetext{
${ }^{1}$ Professora da Universidade Federal do Pará/Grupo de Estudos em Educação, Cultura e Meio Ambiente/GEAM. Programa de Pós-Graduação em Educação/PPGED. Programa de Pós Graduação em Gestão dos Recursos Naturais e Desenvolvimento Local na Amazônia/PPGEDAM.
} 


\section{Introdução}

\section{Aspectos teóricos e metodológicos}

Como romper com as distâncias instituídas entre a floresta e a cidade? Qual prática educativa seria capaz de diminuir esse distanciamento? $O$ presente artigo volta-se para a discussão dessas questões, partindo da premissa de que a possibilidade de construção de sociedades sustentáveis baseia-se no potencial de rearticulação entre os interesses da dinâmica social global e aqueles afetos à cotidianeidade das populações locais.

O presente artigo foi organizado a partir de pesquisa realizada sob o enfoque qualitativo, envolvendo pesquisa bibliográfica e documental, bem como pesquisa de campo junto às comunidades habitantes da Floresta Nacional de Caxiuanã, na Ilha do Marajó, Estado do Pará. O artigo encontra-se dividido em duas partes. Na primeira, intitulada: A aproximação do tema: os encontros entre a floresta e a cidade desafiando a construção de uma nova percepção de natureza, são discutidos inicialmente a percepção que os sujeitos habitantes de cidades possuem acerca da floresta e seus recursos naturais, bem como seus habitantes, vistos de modo mitificado e utilitário. Nesta parte do texto, são apresentadas formulações teóricas a partir de diálogos com autores como Prance (1996), Archer (1995), Simonian (2000), Maimon (1993), Pepper (1987), dentre outros.

A Segunda Parte do artigo, intitulada: O Lugar da Educação Ambiental como comunicação intercultural - a aproximação entre a floresta e a cidade, refere-se a uma tentativa de demonstração de como a Educação Ambiental pode constituir-se como um canal para a aproximação e comunicação intercultural a partir das discussões teóricas propostas por autores como Reigota (1986), Perrot (1994), Faundez (1994), Silva (2001), dentre outros. Ainda nesta parte são apresentados os resultados de pesquisa realizada na Floresta Nacional de Caxiuanã junto aos professores integrantes do Programa de Educação Ambiental desenvolvido pela Estação Científica Ferreira Pena - Museu Emílio Goeldi, relativa às suas concepções e práticas de Educação Ambiental. 


\section{A Aproximação do Tema: os encontros entre a floresta e a cidade desafiando a construção de uma nova percepção de natureza}

A selva dominava tudo. Não era o segundo reino, era o primeiro em força e categoria, tudo abandonado a um plano secundário. E o homem, simples transeunte no flanco do enigma, via-se obrigado a entregar o seu destino àquele despotismo. $\mathrm{O}$ animal esfrangalhava-se no império vegetal e, para ter alguma voz na solidão reinante, forçoso se lhe tornava vestir pele de fera (FERREIRA DE CASTRO, 1930).

A imagem da floresta que habita o imaginário da cidade parece pautar-se no estranhamento, na impossibilidade de compreensão de sua dinamicidade, o que em geral tem levado os sujeitos da cidade a uma espécie de negação da floresta, percebida apenas como recurso, como base para a exploração e reprodução das condições materiais da existência. Essa é a imagem presente no extrato do romance A Selva, de Ferreira de Castro, que abre este artigo. Trata-se da visão de um português que, movido pela necessidade econômica, obriga-se a adentrar no universo desconhecido da Selva para tornar-se um seringueiro, nos idos do ciclo econômico da borracha.

E de lá para cá, o que tem acontecido em relação ao imaginário dos sujeitos urbanos em relação à floresta e seus enigmas? Qual a percepção que esses sujeitos tem dos recursos florestais, e como esses recursos chegam à cidade, e se transformam e cultura, adentrando os espaços da vida da cidade, que continua aparentemente a lhes negar outra origem ou imagem que não aquela baseada no utilitarismo pragmático, ou contrariamente num misticismo absoluto, que considera exótico e com tons de sobrenatural tudo o que se refere à floresta, inclusive suas populações tradicionais.

De acordo com Acher (1995), em artigo sobre comunidades e sustentabilidade florestal, a visão da floresta e de suas populações pode tornar-se um impedimento à melhoria da gestão sustentável dos recurso florestais: 
To many people forests are conceived as apart from human effort. Some see forests as existing in majestic isolation, requiring the exclusion of people. Others view forests as dangerous haunts of snakes and wild beasts, as abandoned lands without 'better' uses of agriculture or grazing (ARCHER, 1995, p. 01).

Vê-se, apesar da manutenção da imagem da região continuamente vinculada à ideia de reserva de recursos naturais necessários à continuidade da dinâmica econômica e social do mundo desenvolvido, que ao longo das últimas décadas a discussão teórica em torno dos problemas ambientais da floresta amazônica vem ganhando contornos de notoriedade face ao agravamento desses problemas. Resta-nos discutir as consequências dessas imagens para as populações amazônicas e a manutenção de sua singularidade cultural associada ao patrimônio de recursos naturais da região.

A produção acadêmica regional evidencia a trajetória histórica de uma política de desenvolvimento fundamentada no culto à lógica do crescimento econômico que nega a diversidade e as potencialidades dos atores sociais locais e suas práticas culturais. Para Simonian (2000, p. 10), as políticas de desenvolvimento regional podem ser categorizadas em torno de três tendências principais:

Uma delas tem suas bases em um passado remoto e simultaneamente no presente dos indígenas, aborígenes e populações similares [...] A outra tendência sustenta-se na teoria econômica clássica [...]. Em face da disseminação do manejo negativo, surgem propostas e reflexões que formam uma terceira abordagem em torno do desenvolvimento sustentável.

As tendências apresentadas por Simonian demonstram-nos uma espécie de embate entre os postulados referentes à valorização exacerbada da cultura local, até certo ponto mitificada, ou idealizada, indicando um retorno puro e simples a um passado de equilíbrio entre as sociedades locais e a natureza - que poderia ser caracterizada como uma visão ecológico preservacionista (MININI, 1994), ou mesmo resultante das teses do 
movimento ambientalista de caráter "blue green" (PEPPER, 1997), e os postulados da economia clássica, cujas premissas fundamentam as práticas negativas de manejo dos recursos naturais, numa clara adoção da lógica antropocêntrica de desenvolvimento que prioriza a supremacia dos interesses econômicos em relação aos fundamentos da sustentabilidade social e ecológica.

Parece-nos evidente que os esforços empreendidos em torno da mudança conceptual e pragmática da lógica do desenvolvimento, traduzidos em novos instrumentos econômicos, ainda não lograram os efeitos desejados, principalmente no campo da consideração das características apresentadas por Acher, que imporiam uma política ambiental que soubesse se relacionar com os interesses dessas populações locais, vistas como as únicas capazes de realização do uso sustentável dos recursos naturais.

Observa-se que em nível global, e especificamente em nível locoregional, a aplicação de políticas de desenvolvimento sustentável não conseguiram surtir grandes efeitos em face de uma série de problemas, que vão desde a formulação de políticas públicas dirigidas ao tratamento desses problemas, o grau de insuficiente aparelhamento do Estado para a fiscalização da implementação dessas políticas, até a ausência de percepção das populações locais e da sociedade mais ampla acerca das necessidades de conservação ambiental. Este último aspecto pode ser evidenciado nas citações abaixo, a primeira, de um estudioso do Ambientalismo Radical na Inglaterra, a segunda, do Diretor Executivo da Reserva da Biosfera da Mata Atlântica:

For the majority of people, living in poverty, dirt and overcrowding in western inner cities or Third World shanties or peasant farms on marginal land, the green politcs of 'hedgerow, butterfly and bunnyrabbit protection' are an irrelevance" Pepper (apud LACEY, 1987, p. 69).

As discussões em torno dos problemas ambientais, ao contrário do que todos dizem, sofreu uma espécie de congelamento no Brasil durante a última década, apesar da Rio-92. Hoje, em virtude do grave aumento dos problemas tidos como de ordem social, 
como a violência urbana, os problemas ambientais continuam sem espaço na agenda política brasileira, bem como nos movimentos sociais organizados: Diante da pergunta: O que é mais prioritário? Deslocar recursos para a construção de presídios e cadeias públicas para a 'contenção' da violência? ou destinar recursos para a realização de programas de conservação ambiental? Parece-me óbvio que equivocadamente, a sociedade política e a sociedade civil brasileira responderiam majoritariamente em favor da primeira alternativa! (Palestra do Diretor Executivo da RBMA, 2002).

Os problemas ambientais do estado do Pará podem ser analisados a partir das formulações em torno do que Simonian chama de manejo negativo, referindo-se a um tratamento dado às questões ambientais sob a lógica do crescimento econômico e do progresso material desconsiderando os custos sociais e ambientais sofridos pelas populações locais, numa nítida separação entre indicativos de conservação e gestão ambiental partilhada. Vê-se que os problemas apresentam-se claramente vinculados a um modelo de desenvolvimento econômico fundamentado na ideia do lucro, e numa visão de natureza como fonte inesgotável de recursos a serem explorados indefinidamente para o atendimento aos interesses do capital.

Esse panorama traçado evidencia uma distância entre a política de gestão implementada e as possibilidades de relações mais definidas entre a conservação ambiental e o uso sustentável dos recursos naturais. Prance (1996) indica que: "The conservation of the Amazon rainforest will only be achieved through a balance between biological conservation in reserves, national parks, indigenous areas and other conservation units and sustainable - use projects"

Para Prance a compreensão das características básicas do ecossistema florestal amazônico que o diferencia de outros ecossistemas é uma necessidade fundamental, na medida em que essas características deveriam nortear as ações relativas à conservação strito sensu, bem como ao uso sustentável dos recursos naturais presentes nos ecossistemas florestais. 
Basta a realização de uma análise mais acurada para perceber-se que a consideração de toda essa gama de complexidade ambiental, e aqui insere-se também a gama de sócio diversidade regional, ainda encontra-se bastante ausente da Política de Gestão Ambiental do estado do Pará.

Diante deste cenário ilustrativo dos problemas ambientais do Estado, voltamo-nos para a segunda parte da pergunta que iniciou esta discussão: para onde vamos? Muitos autores têm se debruçado sobre a análise da problemática ambiental, em especial dos problemas quanto ao uso insustentável dos recursos florestais, conseguindo apontar algumas saídas para o futuro a partir da análise da situação atual das florestas tropicais, (PELUSO, 1991; SPONSEL \& BAILEY, 1996; PRANCE, 1996; SIMONIAN, 2001; ARCHER, 1995). A maioria desses estudos indica a necessidade da consideração dos interesses e práticas das populações locais associadas ao fortalecimento de uma política ambiental que possa deslocar o eixo do manejo dos recursos florestais atualmente existente, tratando-o à luz de suas potencialidades e características peculiares, e articulando uso econômico sustentável às necessidades de conservação ambiental, reaproximando a cultura da cidade à cultura da floresta.

\section{O Lugar da Educação Ambiental como Comunicação Intercultural - a aproximação entre a floresta e a cidade}

Não é possível falar sobre a instalação de um novo paradigma de desenvolvimento com base no discurso teórico da sustentabilidade sem nos aproximarmos das culturas tradicionais, sob pena de estarmos apenas reproduzindo ingenuamente os "chavões" do dicionário hegemônico. A tarefa de compor as condições para essa aproximação traz novas exigências para a formação educacional realizada nas cidades, de modo a inserir nessa formação as preocupações relativas à diversidade cultural das populações amazônicas e sua ecologia e sócio diversidade. Muitos autores vêm construindo formulações nessa área (REIGOTA, 1986; PEPPER, 1987; PERROT, 1994; FAUNDEZ, 1994; SILVA, 2001), indicando a necessidade de revisão da educação e sua estrutura para adequar-se aos

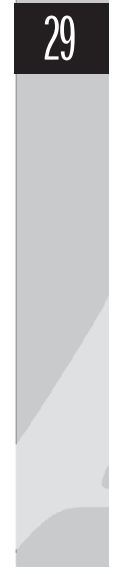


interesses e necessidades das populações marginais latino americanas, sem descuidar das análises relativas à dinâmica global.

Em pesquisa realizada acerca da análise de programas de Educação Ambiental realizados no estado do Pará na década de 90, pôde-se verificar a existência de uma espécie de artificialidade característica de programas elaborados sem a participação dos sujeitos que estarão envolvidos em seu desenvolvimento, que perde terreno, quando ao contrário, esses programas são gerados a partir das reais demandas das escolas e comunidades que atuarão neles, não apenas como executores de uma proposta exógena, mas como gestores de um processo construído coletivamente (SILVA, 2000).

Essa percepção encontra-se demonstrada na análise realizada sobre o Programa de Desenvolvimento Sustentável da Floresta Modelo de Caxiuanã, cujo processo de elaboração e desenvolvimento privilegiou em todas as suas etapas a participação das comunidades do entorno da Estação Científica Ferreira Pena, (Comunidade da Pedreira, do Laranjal e de Caxiuanã). Vê-se, pela análise realizada, que conceitos de grande densidade teórica e objetos de grandes polêmicas acadêmicas, como os conceitos de Educação Ambiental e Desenvolvimento Sustentável, passam a ser incorporados de modo simples e profundo pelas comunidades envolvidas com o programa, pode-se dizer que essa incorporação é mais facilmente compreensível em virtude da relação estabelecida por essas comunidades e a natureza, que é vista como parte indissociável da vida comunitária.

Não existe para essas comunidades uma rígida separação entre as questões sociais, políticas e culturais e as questões e problemas ambientais. A natureza aparece como elemento vital e integrante de todas as dimensões da vida comunitária. Isso significa que apesar das poucas possibilidades de elaboração teórica por parte dos moradores das comunidades envolvidas no Programa de Desenvolvimento Sustentável da Floresta Modelo de Caxiuanã, acerca dos diversos enfoques de análise teórica de temas como educação ambiental e desenvolvimento sustentável, esses temas encontram-se imbricados em suas ações cotidianas na busca por melhorias de suas condições de vida na floresta. 


\subsection{Com a palavra... Os professores da floresta de Caxiuanã}

a) Quanto às concepções de Educação Ambiental e Desenvolvimento Sustentável:

O desenvolvimento sustentável, eu acredito que ele está voltado assim para o nosso dia-a-dia, na qualidade de vida da comunidade e talvez os dois estejam assim e sejam suporte um do outro. No caso, a educação ambiental tem tudo a ver com o desenvolvimento sustentável, por que esse desenvolvimento sustentável, eu acredito que ele tem contribuído no exemplo: Eu preciso de melhorar a qualidade de vida na comunidade, aí eu vou ter que envolver mais alguma coisa já causando até mesmo uma destruição, uma mudança, um processo mais complicado na utilização dos recursos, aí no caso, entraria a educação ambiental pra ver se eliminaria pelo menos um pouco dessa destruição (Entrevista concedida à autora, 2000).

A afirmação acima evidencia uma tentativa do estabelecimento de relação entre o que eles observam através de sua participação nas atividades do programa, seus cursos, oficinas e palestras, e as suas práticas de trabalho cotidiano vinculadas às suas experiências com a comunidade onde vivem.

O exemplo apresentado pela professora traduz uma visão integrada de processos educativos e processos de desenvolvimento, conseguindo apropriar-se das formulações teóricas orientadoras do programa de desenvolvimento sustentável da floresta nacional de Caxiuanã, que apontam para a educação como elemento agregador e irradiador de possibilidades de desenvolvimento sustentável para as comunidades.

Outro elemento a ser analisado é a concepção de dicotomização entre qualidade de vida e desenvolvimento, sendo que qualidade de vida aparece como sinônimo de progresso material, de utilização dos recursos naturais para o provimento das necessidades materiais, e ainda uma potencial causadora de efeitos destrutivos. A educação ambiental serve para tentar solucionar os problemas ocasionados pela melhoria da 
qualidade de vida. Essa afirmação da professora integra o quadro de um célebre equívoco que contrapõe meio ambiente e qualidade de vida.

Percebe-se no depoimento da professora a existência quase naturalizada dessa antítese entre bem-estar social e conservação dos sistemas naturais, apontada por Ferreira, como uma construção histórica do pensamento brasileiro, em função da estruturação política econômica e social do país, que acabam por obscurecer a noção de direitos, e de cidadania, e culmina com o esquecimento daquilo que para a autora parece uma obviedade: o crescimento econômico brasileiro não conseguiu gerar bem estar social para a população brasileira, nem tampouco qualidade ambiental, conforme as informações apresentadas nos relatórios do Índice de Desenvolvimento Humano - Programa das Nações Unidas para o Desenvolvimento (PNUD), nos últimos anos. Para Ferreira: "o IDH conseguiu desvendar o conteúdo ideológico da falsa tensão entre qualidade ambiental e bem - estar social".

Para a professora, a educação ambiental desempenharia a função de remediar os problemas naturalmente ocasionados pela intervenção humana na natureza para a melhoria de sua qualidade de vida, e observese ainda que o conceito de desenvolvimento sustentável, para ela, pode conter em si processos destrutivos justificados pela necessidade do provimento do sustento e pela melhoria da qualidade de vida.

Os demais depoimentos vinculam o conceito de desenvolvimento sustentável à dimensão do provimento de recursos para a existência material, do ponto de vista econômico, porém, quanto à educação ambiental, verifica-se uma ampliação conceitual, que a define como processo educativo amplo, não restrito somente às atividades formais escolares, mas como parte do dia-a-dia da comunidade.

A educação ambiental aparece como provedora de orientações 32 para as ações da comunidade e pode ser percebida como instrumento de conscientização dos povos para um tratamento sustentável dos recursos naturais, e dos problemas sociais.

b) Quanto a ser professor na Floresta de Caxiuanã

Pra nossa criança, pra nossa comunidade, se eu digo que nós temos que derrubar uma árvore e plantar outra, e eu só faço cortar, e não tô nem me ligando 
de plantar outra. O que que eu posso fazer? Eu vou poder cobrar da criança, da comunidade que tire uma e plante outra? Não. Por que eu própria não estou praticando, não estou cuidando do ambiente. E nós sabemos também, que a educação ambiental não é só se preocupar com o meio que nós vivemos, também nós devemos pensar nos cuidados com o nosso próprio corpo, nossa casa, e o homem, ele faz parte, ele é um ambiente também (Entrevista concedida à autora, 2000).

No item relacionado a como é ser professor em Caxiuanã, os depoimentos demonstram uma conceituação para o "ser professor" extremamente vinculada à vida em comunidade, num sentido de perceber-se como sujeito capaz de gerar mudanças na forma como essa comunidade relaciona-se com os recursos naturais que estão à sua volta na floresta.

Os depoimentos indicam para a responsabilidade que o termo "professor" já impõe. A palavra professor aparece revestida de um peso considerável, referente à responsabilidade de atender às exigências dos alunos no que se refere ao saber, à explicação do mundo. Os depoimentos indicam ainda uma dimensão pouco analisada na teoria pedagógica, categorizada como a dimensão da sinceridade "é uma palavra que realmente envolve uma sinceridade". Pode-se apreender dessa afirmação que ser professor implica necessariamente um deslocamento da condição de superioridade tradicionalmente atribuída pela pseudo posse de conhecimentos específicos, para uma posição de igualdade como sujeito humano, naquele momento específico, responsável pelo processo de formação educativa de outros sujeitos igualmente humanos, que assim são tratados. O professor é aquele que precisa estar sinceramente preocupado "em assumir essa responsabilidade muito grande de explicar as coisas que o aluno precisa saber". A noção de ser professor aparece nos depoimentos como vinculada à necessidade de motivar mudanças e agir como um exemplo, não somente para os alunos, mas para toda a comunidade. Apresenta-se uma preocupação muito visível com as próprias ações e com o fato de essas ações não gerarem controvérsias quanto àquilo que eles (os professores) ensinam aos alunos e à comunidade. 
Vê-se ainda que para os professores da Floresta de Caxiuanã, o exercício docente encontra-se vinculado às práticas de conservação dos recursos naturais presentes na floresta. Note-se que, ao serem perguntados sobre como é ser professor em Caxiuanã, todos aludem à preocupações com as orientações para o tratamento adequado aos recursos naturais.

c) Quanto à inserção da educação ambiental nas escolas de Caxiuanã:

- A consideração dos problemas socioambientais da floresta

a natureza vem sofrendo uma modificação, que ela já não é mais aquela natureza, como se diz natural, ela já é modificada né? E isso nós podemos repassar para a nossa criança, que estamos prejudicando não a nós, mas já as gerações futuras, por que daqui há alguns anos, quem sabe se ainda vai existir o açaí, se vai existir a madeira, com todos esses problemas ambientais que as grandes empresas tem, não aqui no nosso meio, mas a realidade hoje é que as grandes empresas elas têm devastado muito a natureza, e com isso, eu acho que causa assim um problema também, e isso nós podemos aplicar também em sala de aula (Entrevista concedida à autora, 2000).

Os depoimentos dos professores demonstraram uma tentativa de inserção das questões ambientais em seu dia-a-dia escolar. As principais questões apresentadas por eles, podem ser analisadas conforme os princípios teóricos e as indicações metodológicas para a educação ambiental, já discutidos em vários documentos de orientações originárias de grandes eventos, tido como marcos históricos da educação ambiental:

- Utilização de procedimentos metodológicos que valorizam a cultura local e os recursos disponíveis na comunidade - Construção da ação interdisciplinar.

Conforme os depoimentos dos professores, pode-se perceber uma tentativa de utilização de métodos que aproximem o saber formal, os conhecimentos contidos nos livros didáticos à cultura da comunidade e suas formas de organização para lidar com seus problemas e necessidades. 
Evidencia-se que o processo educativo pode fundamentar-se na utilização dos recursos naturais presentes na floresta que passam a assumir, para os professores, um papel de recurso didático: é a floresta que ensina, e ensina de modo interdisciplinar. Existe nos depoimentos dos professores um forte componente de articulação entre as várias áreas do saber para a explicação dos conteúdos formais, o que pode denotar uma concepção interdisciplinar de trabalho pedagógico, base para a prática da educação ambiental.

Apresenta-se. ainda, a partir dos depoimentos dos professores, uma discussão de grande relevância teórica: a proximidade com os recursos naturais oferecidos pela floresta cria uma ambiência propícia ao desenvolvimento de práticas de educação ambiental. Nesse sentido, percebe-se que ainda que os moradores da floresta não possuam um grande domínio das discussões teóricas acerca do ambientalismo; ainda que os professores atuantes em Caxiuanã estejam somente agora concluindo seus estudos de formação no curso de magistério, sendo, portanto professores leigos, as suas possibilidades de compreensão do significado da educação ambiental podem ser maiores que a daqueles professores possuidores de maiores níveis de formação teórica e detentores de maior escolaridade que atuam nos grandes centros urbanos.

A diferença entre esses profissionais fundamenta-se numa questão básica: A Sensibilização. Os professores de Caxiuanã, assim como outros professores de escolas ribeirinhas, localizadas no interior de nossas florestas, conseguem dimensionar melhor as práticas educativas para a melhoria das condições ambientais, porque se percebem como parte integrante da natureza.

O estabelecimento dessa diferença, relacionada às potencialidades de implementação da educação ambiental por parte dos professores da floresta, não significa, no entanto, que só é possível realizar educação ambiental em ambientes naturais, isso seria a aceitação de vertente teórica ecológico-preservacionista.

Ao apontar-se para as potencialidades de trabalho de educação ambiental em ambientes naturais como a floresta de Caxiuanã, quer-se demonstrar que professores e alunos desse programa, em virtude de seu maior contato com a natureza, possuem um grau de sensibilização frente 
às necessidades de conservá-la que se diferencia daqueles professores e alunos dos centros urbanos, que já não convivem diretamente com os recursos naturais. Para os professores de Caxiuanã, a ação educativa confunde-se naturalmente com a educação para a conservação de seu meio ambiente.

A análise que se realizou nesse trabalho, demonstra que os pressupostos teóricos e os indicativos metodológicos da educação ambiental podem ser visualizados em práticas educativas realizadas no interior de uma floresta amazônica, com professores e alunos com poucas possibilidades de acesso às grandes produções teóricas da área da educação ambiental.

Para esses professores, o fazer educativo encontra-se necessariamente vinculado à melhoria de suas condições de vida e de sua comunidade, através da melhoria de sua relação com a floresta, que para eles é naturalmente fonte de existência material e humana.

\section{REFERÊNCIAS}

BIFANI, P. Globalization, Medio Ambiente e Desarollo Sostenible. Mexicali, 1998.

COraggio, J. L. Desenvolvimento Humano e Educação. São Paulo: Cortez, 1999.

DOXSEY, Jaime Roy. O dilema da educação ambiental e de seus educadores nas sociedades em transição. In: FAUNDEZ, Antônio (Org.). Educação, Desenvolvimento e Cultura: contradições teóricas e práticas. São Paulo: Cortez, 1994.

GADOTTI, Moacir. Pedagogia da Terra. São Paulo: Petrópolis, 2000.

LEIS, H. O Labirinto: ensaios sobre ambientalismo e globalização. São Paulo: Gaia/Blumenau/ Fundação Universidade de Blumenau, 1996.

LISBOA, P. (Org.). Programa de Desenvolvimento Sustentável da Floresta de Caxiuanã. Belém, 1997. 
Estação Científica Ferreira Pena: ciência e desenvolvimento sustentável na Amazônia. Belém: Museu Paraense Emílio Goeldi, 1999.

LEFF, Enrique. Saber Ambiental: sustentabilidade, racionalidade, complexidade, poder. Petrópolis: Vozes, 2001.

MORIN, Edgar. Ciência com consciência. $5^{\text {a }}$ Ed. Tradução de Maria D. Alexandre e Maria Alice Sampáio Dória. Ed. revista e modificada pelo autor. Rio de Janeiro: Bertrand Brasil, 2001.

PEPPER, David. The basis of a radical Curriculum in environmental Education). In: COLIN, Lacey. Education, ecology and development: the case for in a education network. London: Kogan Page Ltda, 1987. pp. 65-79.

PERROT, Marie Dominique. Educação para o desenvolvimento e perspectiva intercultural. In: FAUNDEZ, Antônio (Org.). Educação, Desenvolvimento e Cultura: contradições teóricas e práticas. São Paulo: Cortez, 1994.

SILVA, Marilena Loureiro. A Globalização como radicalização da modernidade e a construção de um novo lugar para as políticas públicas de educação. Belém: PDTU/NAEA/UFPA, 2002. (aguardando publicação)

SILVA, Marilena Loureiro. Construindo a história da Educação Ambiental no Estado do Pará na década de 90: das escolas de Belém às escolas da Floresta de Caxiuanã. Dissertação de mestrado. Belém: PLADES/NAEA/UFPA., 2000.

MEADOWS, D. et al. Beyond the limits: global colapse or a Sustenaible Future? London Earthscan Publication Limited, 1993.

MEDINA, N. N. Amazônia: uma proposta de Educação Ambiental. Documentos Metodológicos. Brasília: IBAMA.

REIGOTA, M. Meio Ambiente e Representação Social. São Paulo: Cortez, 1986.

RELATÓRIO DE BRUNDTLAND. Nosso Futuro Comum, 1997.

SILVA, T. T. O que produz e o que reproduz em Educação. Porto Alegre: Artes Médicas, 1990. 
SUIRSKY \& CAPOBIANCO. Ambientalismo no brasil Passado, Presente e Futuro. São Paulo: Instituto Sócio Ambiental/Secretaria do Meio Ambiente do Estado de São Paulo, 1997.

TASSARA, E. Educação Ambiental, Referências Históricas, teóricas e formação de redes. Cadernos do IV Fórum de educação Ambiental. Rio de Janeiro: INESC, 1997. 